Spring 4-25-2020

\title{
Occupational Therapy's Role in Pain Management using Virtual Reality
}

Johnathan Quach

University of St. Augustine for Health Sciences

DOI: https://doi.org/10.46409/sr.BAPZ8550

Follow this and additional works at: https://soar.usa.edu/capstones

Part of the Occupational Therapy Commons

\section{Recommended Citation}

Quach, J. (2020). Occupational Therapy's Role in Pain Management using Virtual Reality. [Doctoral project, University of St Augustine for Health Sciences]. SOAR @ USA: Student Capstone Projects Collection. https://doi.org/10.46409/sr.BAPZ8550

This Capstone is brought to you for free and open access by the Student Research at SOAR @ USA. It has been accepted for inclusion in Student Capstone Projects by an authorized administrator of SOAR @ USA. For more information, please contact soar@usa.edu, erobinson@usa.edu. 
OCCUPATIONAL THERAPY'S ROLE IN PAIN MANAGEMENT USING VIRTUAL

\section{REALITY}

by

Johnathan Quach

A Capstone Presented in Partial Fulfillment of the Requirement for the Degree of DOCTOR OF OCCUPATIONAL THERAPY

University of St. Augustine for Health Sciences

April 2020 
OCCUPATIONAL THERAPY'S ROLE IN PAIN MANAGEMENT USING VIRTUAL

\section{REALITY}

by

Johnathan Quach

has been approved

April 2020

APPROVED:

Becki Cohill, OTD, OTR/L, Doctoral Coordinator

Susan MacDermott, OTD, OTR/L, Doctoral Coordinator

Erin Schwier, EdD, OTD, OTR/L, Program Director

ACCEPTED AND SIGNED:

\begin{tabular}{|c|c|c|}
\hline \multicolumn{3}{|c|}{ Becki Cohill, OTD, OTR/L, Doctoral Coordinator } \\
\hline $\begin{array}{l}\text { Susan MacDermott, } \\
\text { OTD, OTR/L }\end{array}$ & 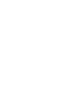 & 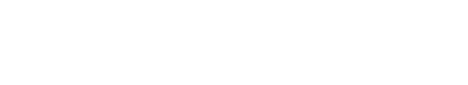 \\
\hline \multicolumn{3}{|c|}{ Susan MacDermott, OTD, OTR/L, Doctoral Coordinator } \\
\hline \multicolumn{2}{|c|}{ eschwier@usa.edu } & 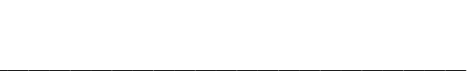 \\
\hline
\end{tabular}




\section{Table of Contents}

Chapter I: Introduction $\quad 5$

$\begin{array}{ll}\text { Background } & 5\end{array}$

$\begin{array}{ll}\text { Statement of the Problem } & 8\end{array}$

$\begin{array}{lr}\text { Purpose statement } & 8\end{array}$

$\begin{array}{ll}\text { Rationale } & 9\end{array}$

$\begin{array}{ll}\text { Significance } & 10\end{array}$

$\begin{array}{ll}\text { Project Objectives } & 11\end{array}$

Assumptions, Limitations, \& Delimitations 11

$\begin{array}{ll}\text { Chapter II: Literature Review } & 12\end{array}$

Occupational Therapy’s Unique Role in Pain Management 12

$\begin{array}{ll}\text { Virtual Reality as a tool for Pain Management } & 13\end{array}$

$\begin{array}{ll}\text { Chapter III: Project Description } & 14\end{array}$

$\begin{array}{ll}\text { Proposed Timeline } & 15\end{array}$

$\begin{array}{ll}\text { Methods } & 15\end{array}$

$\begin{array}{ll}\text { Chapter IV: Results \& Analysis } & 18\end{array}$

$\begin{array}{ll}\text { Analysis of Data } & 18\end{array}$

Interview Results 18

$\begin{array}{ll}\text { Survey Study Results } & 22\end{array}$

Capstone Experience Results 27

Chapter V: Discussion \& Conclusion $\quad 29$

$\begin{array}{lr}\text { Discussion } & 29\end{array}$

$\begin{array}{ll}\text { Limitations } & 29\end{array}$ 
Implications for Occupational Therapy 30

$\begin{array}{ll}\text { Conclusion } & 31\end{array}$

$\begin{array}{ll}\text { References } & 33\end{array}$

$\begin{array}{ll}\text { Appendix A: Email/Phone Script } & 38\end{array}$

Appendix B: Interview Questionnaire $\quad 39$

Appendix C: Copy of Online Survey 41

Appendix D: Weekly Facebook Post/Advertisement for Online Survey 48

Appendix E: Screenshots of Created VR Scenes 49

Appendix F: Informational Handout on VR 54 


\section{Occupational Therapy’s Role in Pain Management using Virtual Reality}

\section{Background}

According to the Pain Task Force of the Academic Consortium for Integrative Medicine and Health, pain care in the United States is in crisis (Tick et al., 2018). The prevalence of pain and pain-related morbidity, mortality and disability continue to persist because medical responses are costly and still rely on pharmaceuticals (Mallari, Spaeth, Goh, \& Boyd, 2019; Garrett, Taverner, \& McDade, 2017). Chronic pain is defined as a recurring pain that persists past the normal healing time of three to six months. This complex phenomenon affects millions of lives every day and is frequently associated with additional decreases in psychosocial health and activity restriction (Garrett, Taverner, \& McDade, 2017; Treede et al., 2015). As evidence accumulates that opioids alone are not the answer, there has been a call to action to increase awareness of effective nonpharmacologic treatments for pain. Prompted by the need for novel treatment strategies to replace or act as an adjunct, healthcare practitioners and administrators must promote ongoing research and dissemination on the role of effective nonpharmacologic treatments in pain management (Gupta, Scott \& Dukewich, 2018; Tick et al., 2018; Wiederhold, Miller, \& Wiederhold, 2018).

Of these nonpharmacologic treatments for pain, the use of virtual reality (VR) has been shown to be an effective adjunct and alternative to conventional analgesics (Foran, 2011). VR is a simulated, interactive, 3-D environment that allows an individual to experience sensory information, such as vision, touch, and sound, through the use of videogaming or computerbased systems (Foran, 2011). These systems typically involve a head-mounted device, a videocapture method, and special equipment that provide its users haptic input (i.e. position, weight, texture of virtual objects) that can be applied alone or in combination with physical or cognitive 
interventions (Roosink \& Mercier, 2014). Even more advanced VR systems involve the use of projections in high-tech rooms that allow an individual to become fully immersed in a virtual environment (Foran, 2011). Transported into a virtual world, individuals suffering from pain are engaged in an experience that can act as a nonpharmacologic form of analgesia.

Numerous studies in the past two decades have demonstrated that VR can be an effective tool in reducing pain. VR-based interventions have been used to decrease pain among individuals undergoing painful medical procedures such as burn injuries, wound debridement, and even dental procedures, with the "gate control" theory of distraction being the most widely accepted model used to explain its effects (Li et al., 2011; Keefe et al., 2012). The gate control theory, which suggests that attending to a stimulus different from pain can help "block" certain pain messages from making its way to the brain, supports the nature of VR technology. Essentially, the theory postulates that VR can block an individual's sense of pain by absorbing and diverting their attention away from the pain with its integration of multi-modal (i.e. visual, auditory, tactile and olfactory) sensory distractions (Li et al., 2011).

Recent literature has also revealed VR's effectiveness in reducing pain by altering one's pain perception. According to Alazba, Al-Khalifa \& AlSobayel (2018), pain can be effectively reduced with an immersive VR system that addresses the Fear Avoidance Model. The Fear Avoidance Model suggests that the development of pain in individuals differ based on their levels of pain-related fear of movement, also known as kinesiophobia (Alazba, Al-Khalifa \& AlSobayel, 2018). As such, those who are more prone to catastrophize pain are also more likely to exaggerate their pain or falsely perceive it as a sign of seriously harm or damage. Because of this, these individuals will tend to avoid movement and even physical activities altogether (Alazba, Al-Khalifa \& AlSobayel, 2018). By addressing this fear of movement, VR has the 
ability to alter one's pain perception, thereby allowing them to not only move, but thrive in a less painful environment (Fowler, Ballistrea, Mazzone, Martin, Kaplan, Kip, Murphy, \& Winkler, 2019).

Garcia-Palacios et al. (2015) explored the potential use of VR as a behavioral intervention for managing pain and addressing the fear of movement. Using a VR adaptive display, a team of researchers developed content to successfully motivate participants with fibromyalgia to get involved in activity management rather than focus solely on pain management. According to Garcia-Palacios et al., 2015, through the use of an integrated VR/behavioral intervention, participants gained control over their pain and were more motivated to practice specific strategies in their natural environment. This ultimately allowed for greater participation in valued activities (Garcia-Palacios et al., 2015).

Several other studies have also shown VR's ability to help individuals overcome their fear of movement due to pain, including those with impaired movements due to hemiplegia, hip pain, lower back pain, multiple sclerosis, and even Parkinson's disease (Walino-Paniagua et al., 2019; Alemanno et al., 2019; Alazba, Al-Khalifa \& AlSobayel, 2018; Aran, Sahin, Torpil, Demirok \& Kayihan, 2017; Bolte, Lussanet, \& Lappe, 2015; Kim, Min, Kim \& Lee, 2014). Through the use of interactive virtual representation of limbs, VR has recently been shown to even reduce neuropathic and phantom limb pain (Wittkopf, Lloyd, Coe, Yacoobali \& Billington, 2019).

By distracting pain and facilitating purposeful movement, VR can significantly reduce one's risk for greater functional disability, improve their ability to perform desired activities, and more importantly, improve their coping ability so that they can better manage their pain experience (Fowler et al., 2019; Alazba, Al-Khalifa \& AlSobayel, 2018). However, like opioids, 
the use of virtual reality alone cannot effectively improve an individual's pain management. Years of evidence-based research have suggested that multidisciplinary rehabilitation is the most efficient form of intervention for pain, with occupational therapy particularly effective in treating chronic pain (Hesselstrand, Samuelsson, \& Liedberg, 2015). With the use of interventions and training components such as graded and purposeful activity, environmental modifications, therapeutic exercise and psychologically based management strategies, occupational therapy's contribution to pain management is extensive and has been well-documented (Robinson, Kennedy, \& Harmon, 2011). Thus, reviewing the use of VR in conjunction with occupational therapy services for pain management is warranted.

\section{Statement of the Problem}

While there is substantial evidence for VR use in acute situations, literature on VR use to reduce chronic pain is still in its infancy, and even less literature is currently available on the use of VR in conjunction with occupational therapy to manage pain and improve quality of life. More research and development are currently needed to outline the role of VR in the management of pain and how they can best be integrated within occupational therapy practice.

\section{Purpose Statement}

Occupational therapists provide a wide range of pain management interventions and have the knowledge, skills, and expertise to address pain in all its complexity (Lagueux, Depelteau \& Masse, 2018). With the ability to analyze and adapt to the demands of daily activities and occupations, occupational therapists are very well suited for utilizing interventions like virtual reality to mediate one's pain experience. The purpose of this capstone project then, is to determine and outline the appropriate and potential role of virtual reality within the scope occupational therapy practice concerning pain management. 


\section{Rationale for Proposed Project}

Occupational therapy is a client-centered profession that helps individuals suffering from participation and occupational performance limitations as a result of pain. By offering a wide range of rehabilitation strategies, occupational therapy can provide individuals with the appropriate support needed to enhance functional ability, enable participation in meaningful daily activities, and improve overall occupational performance. Occupational performance refers to the point when the person, the environment, and the person's occupation intersect to support the tasks, activities, and roles that define that person as an individual (Baum \& Law, 1997). Within the context of chronic pain, an occupational therapist is fully equipped to evaluate the pain's impact on an individual's quality of life and offer the individual skills and strategies needed for managing the pain while maintaining participation in his or her desired activities (Hofmann, 2018). Occupational therapists can also show these individuals how to redirect their pain so that it interferes less with the quality of their daily lives (Hofmann, 2018).

Guided by the cognitive-behavioral frame of reference, occupational therapists can help an individual not only by distracting and relieving their chronic pain, but also by facilitating the individual's reconceptualization of his or her own ability to control pain (Robinson, Kennedy, \& Harmon, 2011). This is done by focusing on both behavioral and cognitive components of chronic pain, including its relation to an individual's cognitive, affective and physiological issues (Duncan, 2011). Like virtual reality, occupational therapy's approach to pain is multi-modal and can include treatment methods such as relaxation training, visualization, as well as practice and consolidation of coping skills through role-playing and other behavioral techniques (Hofmann, 2018). 
By addressing the disruptions in occupational performance caused by pain, occupational therapists are also concerned with the occupational identity of their client. The Model of Human Occupation states that "occupational identity" constitutes the values, beliefs, roles, and interests which drive a person to perform daily activities. Occupational therapists recognize that pain can affect all areas of a client's life, including their competency and identity. They are trained to use a holistic approach to address the occupational needs of clients living with this problem (Lagueux, Depelteau \& Masse, 2018). They are better able to understand the relationship between one's participation in occupations and his or her health and subsequently, they can determine participation-oriented interventions that best provide clients with the support needed for involvement in their daily activities despite pain (Lagueux, Depelteau \& Masse, 2018).

\section{Significance of the proposed project}

Chronic pain can negatively impact independence, work performance, family and social role fulfillment, community participation, physical activity, leisure, sexual relations, roles, and self-care performance (Robinson, Kennedy, \& Harmon, 2011). As a crucial part of a pain management team, occupational therapists should be part of the call to promote ongoing research and dissemination on the role of effective nonpharmacologic treatments for pain. Utilizing the person-in-context and their skill in adapting and modifying, occupational therapists have been successful in creating powerful and meaningful intervention strategies. Because of this, occupational therapists must take steps towards the exploration, development and use of virtual reality for even more comprehensive pain management.

VR has the ability to reduce pain by exerting an array of emotional, cognitive and attentional processes on the body's intricate pain modulation system (Li et al., 2011). Occupational therapists can utilize this ability to help change the way individuals cope with pain 
on a daily basis and maximize their capacity for engagement in meaningful occupations. More importantly, as an alternative, nonpharmacologic method of treatment for managing pain, occupational therapy can explore the potential use of virtual reality as part of the larger answer to our nation's current pain crisis. Once known for its use as an entertainment tool, VR has the potential to become an extremely valuable therapeutic tool in the field of healthcare and pain management.

\section{Project Objectives}

1) Identify populations and conditions that currently apply VR interventions

2) Assess the effectiveness of VR for various populations through literature search and expert interviews.

3) Observe the use of VR for pain in various populations and evaluate its application to occupational therapy scope of practice

4) Interview/Survey individuals to determine current awareness, interest, perceptions, and barriers to VR use

5) Combine information from observations, literature search, and expert interviews and surveys to formulate an appropriate role for OT use of VR in practice and communicate findings to the profession.

\section{Assumptions}

- Current pain interventions are insufficient

- Patients are looking for alternative treatment for their chronic pain

- Chronic pain affects occupational performance and participation

- VR is an appropriate modality for OT use in the treatment of chronic pain

- Activities and skill development in the virtual world will translate into real world 


\section{Limitations}

- Lack of control over the different patient populations seen at site of capstone project

- Accessibility/availability of virtual reality technology

- Pain is so limiting that patients are unable to come in for treatment

- Patients may not be receptive to virtual reality

\section{Delimitations}

- Chronic pain management as opposed to acute pain management

\section{Chapter II: Literature Review}

A gap in the literature exists between the role of occupational therapy in pain management and the use of virtual reality (VR) as a pain management tool. Thus, two significant themes must be examined in order to further understand the purpose of this proposal and to justify the need for further exploration into the role of occupational therapy in pain management using virtual reality. These themes include: 1) Occupational Therapy’s Unique Role in Pain Management and 2) Virtual Reality as a tool for Pain Management.

\section{Occupational Therapy's Unique Role in Pain Management}

Historically, opioid medications have been used for pain management. However, current literature continues to point to the negative side effects of opioid use, including delays in recovery, increased risk of permanent disability, increased hospital admissions, and increased health-care costs (Mallari, Spaeth, Goh, \& Boyd, 2019). A growing body of evidence also suggests that occupational therapy continues to make unique contributions to pain management. As members of a pain management team, occupational therapists have been successful in helping individuals manage pain by using of noninvasive, purposeful interventions that promote movement, alter moods, divert pain from the mind, and provide a controlled amount of stress can 
potentiate physiological mechanisms associated with pain reduction (McCormack, 1988).

Several effective treatment methods found in literature include the use of equipment provision, body mechanics and postural education, biofeedback, relaxation training, visualization, and psychologically-based management strategies, including cognitive-behavioral therapy (CBT), and other behavioral or psychotherapeutic approaches (Robinson, Kennedy, \& Harmon, 2011; Hofmann, 2018).

Chronic pain significantly disrupts occupational performance and research has suggested that engaging in occupation has the potential to mediate the pain experience and to alter biological, psychological, and social factors that are known to influence the pain experience (Robinson, Kennedy, \& Harmon, 2011). Occupational therapists should be part of the call to promote ongoing research and dissemination on the role of effective nonpharmacologic treatments for pain. Further exploration on occupation-based interventions and their effectiveness will aide in addressing specific occupational issues related to individuals living with chronic pain on a daily basis.

\section{Virtual Reality as a tool for Pain Management}

Evidence in the field of pain management suggests that virtual reality (VR) has the ability to reduce pain. A majority of literature over the last decade supports the use of VR as an effective tool in reducing acute pain experienced during various medical procedures, including labor contractions, episiotomy repair, dental procedures, wound debridement, and remobilization of range of motion for joints limited by burns (Foran, 2011; Li et al., 2011; Keefe et al., 2012; Mallari, Spaeth, Goh, \& Boyd, 2019). Evidence also exists to support the use of VR as an adjunct for pain medication (Garrett et al., 2014). Furthermore, VR literature provides evidence that VR can enhance an individual's capacity to manage chronic pain conditions, such as 
subacromial impingement syndrome, dorsalgia, and cervicalgia, through distraction and building of functional skills to modulate the processing of pain sensation (Ahmadpour et al., 2019).

Distraction is a strategy well known in pain studies, and current literature proves distraction to be the most commonly used strategy in pain management (Matsangidou, Ang, \& Sakel, 2017). Taking pain out of the equation typically correlates with improved coping ability, improved ability to learn or relearn desired activities, and an overall reduced risk for greater functional disability (Alazba, Al-Khalifa \& AlSobayel, 2018).

However, despite emerging evidence, consensus on the effectiveness of VR as a tool for pain management remains inconclusive. This is in large part due to the fact that, as an intervention, the use of virtual reality alone cannot effectively improve an individual's pain management. More so than issues concerning the accessibility and portability of VR, is the lack of evidence-based research to support its use in pain management by health professionals, particularly clinicians in the field of rehabilitation (Mallari, Spaeth, Goh, \& Boyd, 2019). Therefore, in order to bridge this gap in literature, further exploration into the role of occupational therapy for pain management using VR is needed.

\section{Chapter III: Project Description}

The purpose of this capstone project is to explore the potential role of virtual reality as an adjunct to occupational therapy in the treatment of chronic pain. This project was to be completed at various locations or sites. The goal was to visit a virtual reality site currently applying virtual reality technology in combination with physiological monitoring and feedback for training, therapy, and emerging applications. In addition, the doctoral student also aimed to visit a clinic with a pain management program in order to survey individuals and gather their perspectives and/or awareness on the use of virtual reality for pain. To be more specific, the 
doctoral student wished to survey a variety of individuals. These individuals included those with chronic pain who have not used VR, those with chronic pain who have used VR, those who have used VR for other conditions, staff/therapists who use VR for pain, staff/therapists who use VR for non-pain related conditions, and finally, staff/therapists in pain programs that may be considering using VR. This project began in November of 2019 and end in the spring of 2020.

\section{Timeline}

The project was carried out over a 16-week period. At the capstone site, the doctoral student took the time to familiarize with staff and all operations related to the facility. The doctoral student also participated in observational sessions in order to learn more about the VR programs and the latest equipment available. This included learning sessions on how to operate various VR systems as well how to complete treatment using VR. In addition to observations done at the virtual reality site, a needs assessment on the chronic pain population was conducted. A needs assessment allowed the doctoral student to identify the current needs of the chronic pain population in order to determine the feasibility of virtual reality use. The needs assessment included reviewing current literature, conducting an online survey study, as well as interviewing health professionals.

The final weeks of the capstone experience involved the doctoral student carrying out the proposed methods of the project. This included the collecting of data gathered from interviews, observations, and surveys as well as the analyzing of data for themes found. All findings were then put together for a final poster presentation.

\section{Methods}

Altogether, the methods of this capstone project consisted of three components: 
1. A set of interviews with health professionals with expertise in either pain management, virtual reality research, or both.

2. An Institutional Review Board (IRB) approved study on the perspectives of therapists regarding the use of virtual reality

3. A capstone experience completed at PoNG, a neurogaming center at the University of California, San Diego (UCSD) specializing in virtual reality gaming development.

As part of a need's assessment, the first component of the capstone project involved the doctoral student completing initial interviews with various health professionals with expertise in either pain management, virtual reality research, or both. These interviewees were found and recruited through either a literature search, various Facebook networks such as "OT4OT" and "Pain4OT", or by word of mouth. The doctoral student contacted each interviewee by means of phone call and/or email using a prepared script (See Appendix A). Interviews were conducted at the convenience of the interviewee via email, video, and/or in-person and were based off a short questionnaire created by the doctoral student (See Appendix B). The interviews took place between December 2019 and March 2020 and were focused on virtual reality's potential in the world of pain rehabilitation. Interview responses were collected, recorded, and/or transcribed as soon as they were completed.

In addition to the interviews, the capstone project also involved conducting an online survey study approved by the University's Institutional Review Board. Using Google as the platform, the doctoral student created an online survey questionnaire (See Appendix C). The survey comprised of 16 questions and included a mix of demographic, open-ended, close-ended, rating scale, and dichotomous questions. Participants for this study were recruited through the 
"OT4OT" and "Pain4OT" networks on Facebook. A weekly post was created and advertised by the doctoral student from February through the end of March 2020 (See Appendix D). The aim of this online study was to determine the perceptions and attitudes from a community of therapists who have experience with virtual reality, as well as those who have not had experience with virtual reality. The study also wished to assess their willingness and motivation to try virtual reality in their own practice setting while uncovering any potential or perceived barriers to virtual reality use. Finally, by exploring and examining the perceptions of practicing therapists in the community, the online study ultimately sought to enhance occupational therapy practice in the field of pain management by creating awareness for the potential use of virtual reality as an effective treatment intervention.

The final component of the capstone project involved the doctoral student completing a capstone experience at PoNG. PoNG, which stands for Power of Neurogaming, is a center that seeks to create games that meet a wide range of goals, including medical rehabilitation, behavioral intervention, and learning across the lifespan. The team at PoNG combine neuroscience knowledge in the areas of motivation, learning, movement, and physiology with current and cutting-edge technology like virtual reality in order to create integrative platforms, tools and best practices for developing and delivering games. While at PoNG, the doctoral student completed nearly 200 hours of observations and had the opportunity to learn about virtual reality in greater detail, including learning about different virtual reality equipment and platforms, certain virtual reality programs for gaming and gaming development, as well as virtual reality studies currently being conducted or developed. The doctoral student was also able to take part in the development of a virtual reality game, which afforded the student with the unique opportunity to learn how to create various virtual environments. 


\section{Chapter IV: Results and Analysis}

\section{Data Analysis}

Data analysis for this capstone project consisted of identifying common themes or concepts derived from the interviews, surveys, and capstone experience and were done after each component was of the project was completed. The doctoral student closely examined the data that was recorded to identify common themes - topics, ideas and patterns of meaning that came up repeatedly throughout the capstone project.

\section{Interview Results}

Upon completion of a data analysis on the six interviews conducted, the doctoral student came to several meaningful conclusions regarding the potential use of virtual reality in pain rehabilitation: 1) VR can provide context that is ecologically valid and safe; 2) VR allows rehab professionals to take therapy anywhere; 3) VR enables health professionals to better understand the patient experience; 4)VR can help establish better connections in the brain; 5) VR environments can be tailored to meet all kinds of needs - particularly pain; and 6) Health professionals must collaborate more with VR developers in order to fully capture its potential in the world of healthcare and pain management.

\section{VR can provide context that is ecologically valid and safe.}

As with any intervention or treatment modality, the concern is always whether or not it can be generalizable to the real world. Can success found in a virtual environment be transferred into a real-world environment? In the eyes of some practicing therapists currently conducting research on the use of virtual reality, it can.

... I believe virtual reality is ecologically valid because it creates a sense of 'being there' and this idea of 'being there' is connected to one's psychological and physical presence. What's more, by addressing and engaging all of one's senses, all the visual, auditory, and 
haptic senses in real-time, we really are able to address a patient's functional needs in a manner that closely resembles real-world functional abilities. - Interviewee \#1

I mean... it's in the name, the word 'reality.' Yes, it's a 'virtual' reality, but the idea is to create the best version of 'reality' possible. If we are able to do that, we are surely able to transfer skills and success found virtually... Obviously there are many other factors that must be addressed, of course. - Interviewee \#4

VR is not a standalone treatment, but it can give you the capacity to do things that can be transferred into real world settings - Interviewee \#5

\section{VR allows rehab professionals to take therapy anywhere.}

Advancements in technology has allowed for greater access to its use both recreationally and in clinical or professional research. Virtual reality in particular has been gaining momentum as a technology of choice for researchers and developers due to its portability and growing number of platforms.

...Virtual reality is a technology that continues to advance and is quickly becoming not only more affordable, but also easier to use and easier to take with you anywhere you go... - Interviewee \#2

One of the best parts about virtual reality is the fact that you can create any type of environment you want or need and use it in a setting you would normally not think is possible. - Interviewee \#5

You may not be able to play tennis in a clinic, or cook food while in a hospital, but with virtual reality, you can... That is a great advantage to have. -Interviewee \#6

\section{VR enables health professionals to better understand the patient experience.}

Often, it may be difficult for health professionals to truly empathize with a patient because they are unable to witness the actual difficulties or struggles that a patient is going through. Virtual reality may be able to help bridge that gap by giving health professionals another method to observe and understand a patient and his or her experience.

When a client is going through a simulation of a traumatic event, for example, the therapist is seeing it. I mean, they're seeing what the patient sees in the simulation... I think in some ways, they're getting closer to the patient compared to just the patient's narration as they imagine it in their head. - Interviewee \#3 


\section{VR can help establish better connections in the brain.}

Consistent with findings mentioned in the literature, several interviewees with expertise in pain management believe that movement is a necessary component pain rehabilitation. More specifically, guided learning or relearning of functional movement is an important aspect of any pain management or rehabilitation process. Virtual reality technology may be used to promote better motor learning in rehabilitation.

VR can establish better connections in the brain as you work toward concrete goals. This can lead to more complete recovery from pain or other movement restrictions. Interviewee \#4

I have used games for pain management as a vehicle for people to learn to develop their activity management skills while in the middle of an exciting and attention-grabbing game. It has been a very big success for the people I work with, and a lot of fun for everyone! - Interviewee \#5

We can use VR for added intensity and repetition that cannot be obtained currently in the real world... to gain that extra or needed capacity to do things. - Interviewee \#6

\section{VR environments can be tailored to meet all kinds of needs - particularly pain.}

Literature continues to point towards the use of virtual reality as an effective method of treatment used to meet various rehabilitative needs, including reducing pain and enhancing quality of life. According to several interviewees, part of virtual reality’s appeal and effectiveness is its unique ability to be adapted, designed, or tailored.

The possibilities with VR are endless. Limitless. Only bound by your imagination and how skilled you are at choosing or designing your environment... However, you need to have certain knowledge or skills in order to understand that process for your patients. Interviewee \#1

We have done a pilot study that showed promising results in pain reduction (even after the session), increased participation, and improved mood. - Interviewee \#4

One of the best parts about virtual reality is the fact that you can create any type of environment you want or need and use it in a setting you would normally not think is possible. - Interviewee \#5 


\section{Importance of Collaboration with VR Developers.}

No longer just an afterthought, virtual reality has the potential to be the next big thing as an emerging tool in healthcare and rehabilitation. However, health professionals with experience in virtual reality research are careful with their praise of virtual reality because they understand several barriers continue to persist, particularly with the lack of awareness and buy-in from individuals that are most qualified to use it a health care setting. Health professionals must collaborate more with VR developers in order to fully capture its potential in the world of healthcare and pain management.

VR technology continues to get better and better but requires the direction of health professionals in order to safely and accurately meet the needs of the populations they serve. - Interviewee \#1

There are many studies out there, but so far, just studies. We need more buy-in and we need more awareness in the rehab world. More people working with those who know VR. Unfortunately, there are also always skeptics... which makes it difficult. - Interviewee \#4

Unfortunately, while we continue to make strides, we still have yet to get over the hump. It's a good thing that you're doing this research. To get the word out there. VR can definitely help a lot of people. - Interviewee \#6

\section{Survey Study Results}

Data analysis for the online survey yield some positive results regarding the potential for occupational therapy's role in pain management using virtual reality. Overall, there were a total of 41 responses. Outlined below are some of the key takeaways from the survey analysis:

A majority of therapists indicated having had some VR experience, and those who had reported a positive experience, used words such as "cool", "fun”, "engaging", "immersive”, or "enjoyable" when asked to describe their experience. 
Have you ever used or experienced virtual reality for leisure?

41 responses

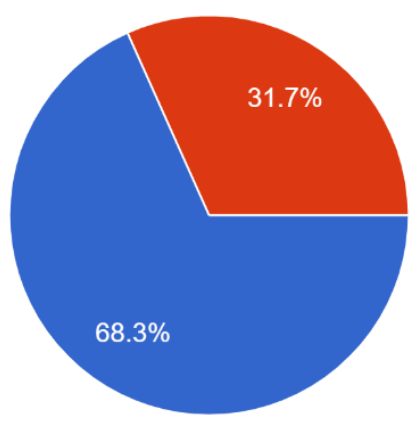

Figure 1. Survey answers to the question on whether participants have used or experience VR before.

Slightly over half of participants have seen virtual reality used in a clinical setting. These settings include acute rehab, SNF, outpatient rehab, neuro rehab, home health, and inpatient psych. When asked to describe their thoughts on VR use, responses included: driving simulation, pain distraction while working on ADL training, stroke recovery, graded motor imagery, mood disorders, graded exposure for phobia, balance and postural control training, sensory integration, amputation, desensitization, and visual training.

Have you ever used or seen virtual reality used in a clinical setting?

41 responses

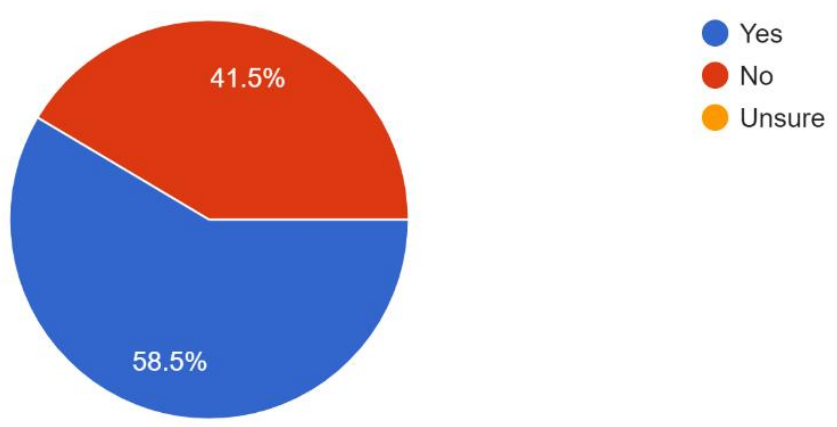


Figure 2. Survey response to the question on whether participants have used or seen VR used in a clinical setting.

A similar number of responses indicate that participants are currently aware that virtual reality is being used to treat and manage pain. When asked to indicate what setting or population they have seen using VR, responses included: amputees with phantom limb pain, burn and cancer procedures, chronic pain, spinal cord injuries, mindfulness training, and kinesiophobia.

Are you aware that virtual reality is being used to treat and manage pain?

41 responses

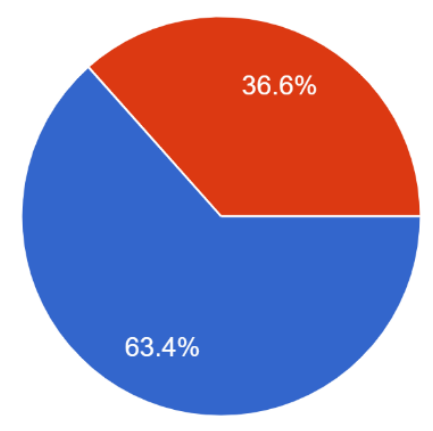

Figure 3. Survey answers on whether participants are aware that virtual reality is being used to treat or manage pain.

All participants believed that it was important to keep up to date with the latest advances in technology. 78\% (32) of respondents rated "very important" and 22\% (9) rated "important." 
Do you believe it is important for therapists to keep up-to-date with the latest (evidence-based) advances in technology? Please answer this question by using the scale below.

41 responses

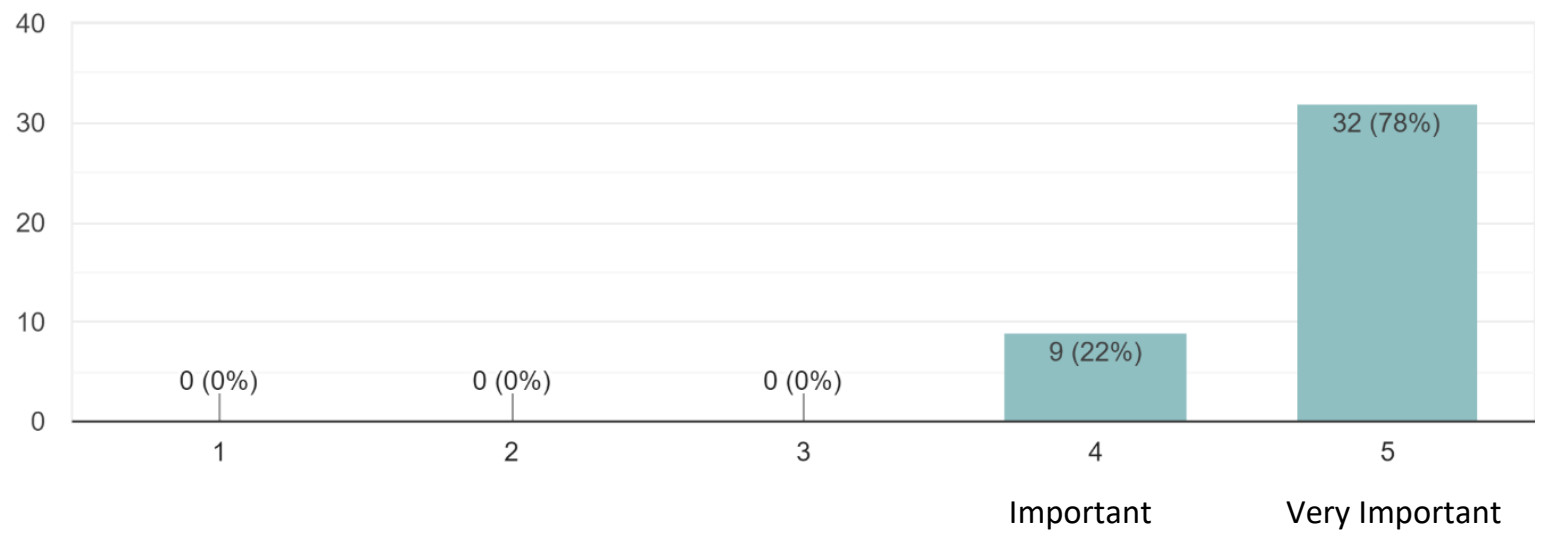

Figure 4. Survey responses when asked to rate level of importance on keeping up to date with latest advances in technology.

Almost all participants believed there is a need for novel pain treatments to replace traditional medicine and rehabilitation practices. When asked about the perceived benefits of utilizing advanced technology, such as virtual reality, responses typically supported it's use in rehabilitation. Some of the responses are outlined below:

- "It can allow a patient to perform an activity in a safe setting and can be adjusted to their needs/abilities."

- "Patients can interact with objects in a safe environment."

- "The patient's thoughts are directed away from their body. Greater freedom of movement is achieved, and the patient does not have the visual input from the painful body part."

- "Distraction, relaxation... improved participation due to reduction in fear of movement and possibly due to changes in the brain (decrease in central sensitization, etc)." 
- "Nonpharmacological intervention with less risk of side effects...May be perceived as more novel and interesting to clients... May be more cost-effective long term."

- "Distracts patient from illness or pain, increases self-efficacy, may help manage depression."

- "Improved functional recovery."

Many of the participants of the study also rated highly when asked if they would be interested in learning more about virtual reality for pain management. 52.5\% rated "very interested", 25\% rated "interested", $20 \%$ rated "somewhat interested" and only $2.5 \%$ rated "not interested."

How interested are you in learning more about virtual reality and how it can help manage pain? 40 responses

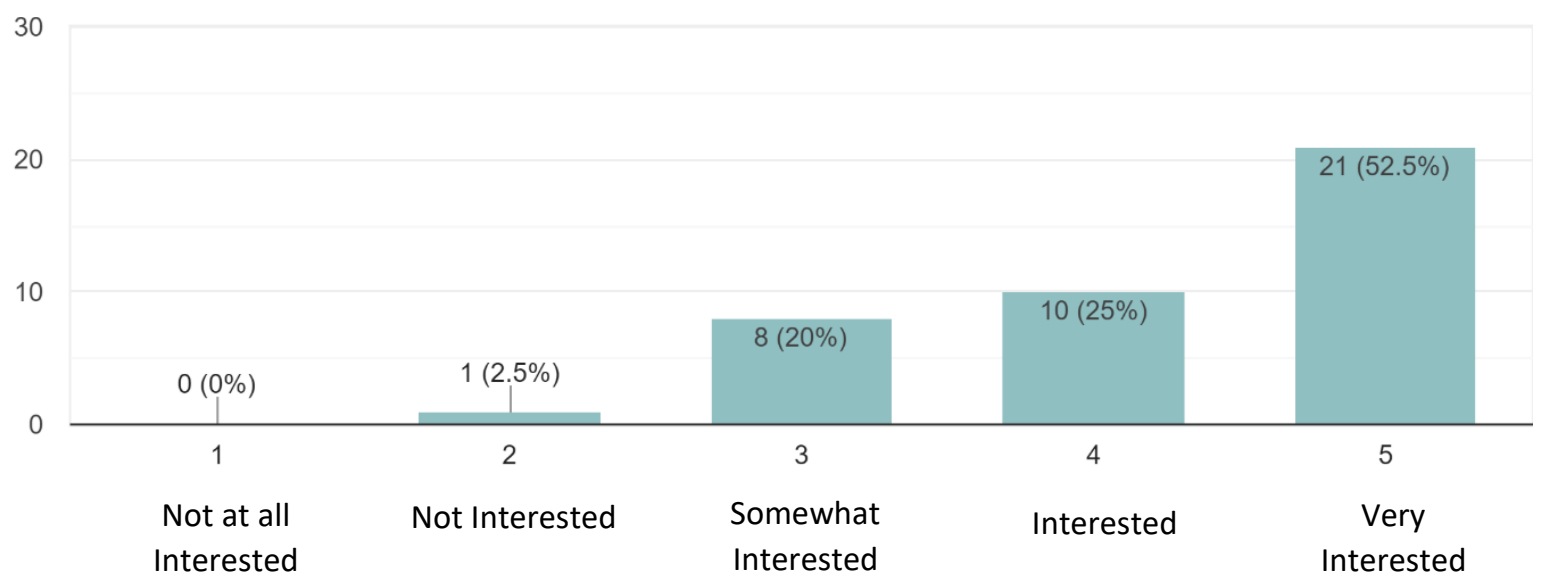

Figure 5. Survey responses when asked to rate level of interest in learning more about VR in pain management.

Reponses were fairly similar when asked to rate interest in incorporating virtual reality in their own practice settings. $36 \%$ rated "very interested", $24.4 \%$ rated "interested", $31 \%$ rated 
"somewhat interested", $2.4 \%$ rated "not interested", and 4.9\% of participants rated "will never be interested."

How interested are you in incorporating the use of virtual reality in your own setting?

41 responses

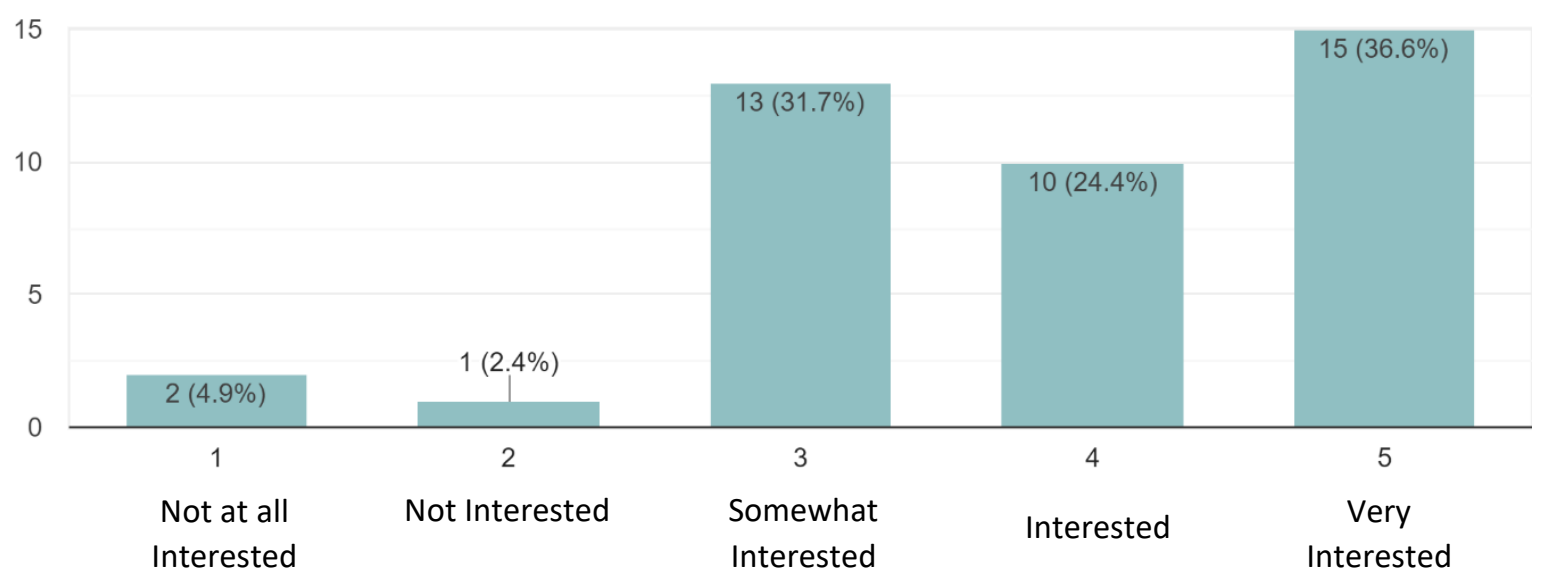

Figure 6. Survey responses when asked to rate level of interest in incorporating VR in their own settings.

Finally, when asked about perceived barriers to virtual reality use in clinical settings, many participants shared similar opinions. Of the many barriers mentioned, cost, time constraints, practitioner competency, infection control, client/patient interest, and lack of evidence were most often brought up. Other barriers include reliability and quality of equipment, infection control, and concern about home carryover.

\section{Capstone Experience Results}

As mentioned above, the capstone experience at PoNG afforded the doctoral student with the opportunity to observe and learn more about virtual reality. This included learning how to use and access certain VR equipment and platforms, learning about the different VR programs available for gaming and gaming development, as well as learning about the various VR studies currently conducted or developed both at UCSD and around the world. 
In addition to these learning opportunities, while at PoNG, the doctoral student also had the chance to develop a virtual "game" or environment. The doctoral student was asked to create a scene that could be used hypothetically to treat a patient with chronic pain. In doing so, the doctoral student developed a unique appreciation for the process of developing virtual reality games. Much like an activity analysis, the task of creating a virtual environment required the doctoral student to break down each individual component related to a task or movement. As a result, the doctoral student was able to create a "game" that addressed certain aspects of pain rehabilitation, such as using guided imagery and graded exposure, incorporating and encouraging fine and gross motor movements like grasping, and forward and overhead reaching, and finding balance, maintaining proper posture, and following proper biomechanics. Some of the scenes created by the doctoral student were screenshotted and can be found in Appendix E.

This particular capstone experience provided the doctoral student with valuable information on virtual reality - information that must be shared with the profession of occupational therapy in order to create more awareness for the potential use of virtual reality as an effective treatment intervention. A deliverable in the form of an informational handout represents the culmination of this capstone experience and can be found in Appendix F. After graduating, the doctoral student will continue to participate in research regarding virtual reality use and explore possible opportunities for dissemination of information found on the handout. These opportunities may include developing a virtual reality program, presenting at regional or national conferences, speaking at universities, and publishing to occupational therapy journals.

\section{Chapter V: Discussion \& Conclusion}

\section{Discussion}


The capstone project was intended to be completed at multiple sites. Unfortunately, a change in funding and facility operations resulted in the cancellation of one particular site and the elimination of a portion of the doctoral student's capstone experience. Due to this unforeseen circumstance, the doctoral student was unable to complete in-person observations or interviews with health professionals or their patients. However, while this eliminated some research in a pain management setting, the doctoral student was still able to complete the capstone project.

The results of this capstone project support existing literature on the efficacy of using virtual reality as an intervention for rehabilitation and for pain management. There is little doubt today that virtual reality can be an effective and safe alternative form of treatment for various pain conditions. This was demonstrated through the expert interviewees. Each interviewee expressed their support for the use of virtual reality. Themes that emerged from the interviews suggest that, as an adjunct intervention, virtual reality can be effective, safe, and ecologically valid. Furthermore, as a tool for pain management, virtual reality can be useful to a practicing clinician because it has limitless potential and can take therapy anywhere, anytime. However, several interviewees also stated that successful use of virtual reality requires competency and direction. These interviewees cautioned that it is not as simple as putting on a headset and turning on and off a button. Virtual reality technology must be understood and used appropriately and thoughtfully by clinicians in order to safely and accurately meet the needs of the populations in which they serve.

The findings of this capstone project also demonstrate that a role certainly exists for virtual reality within the scope of occupational therapy practice. The results of the online survey study reveal that a majority of therapists are aware of virtual reality technology and have seen it used in clinical settings. The results also suggest that keeping up to date with advances in 
technology, like virtual reality, is of great importance. This was indicated by the strong response rate to the question, as all 41 participants believed it was either "very important" or "extremely important." Finally, the results showed that therapists generally believe virtual reality can benefit their patients. Many responses described virtual reality as fun, engaging, novel, and versatile. When asked about the perceived benefits of utilizing virtual reality as a therapeutic intervention, several common themes were found. Virtual reality can benefit therapy by increasing motivation and self-efficacy, improving engagement or reengagement in meaningful activities, preventing opioid dependence, and creating positive experiences that are expertly tailored and more clientcentered, thereby transcending the limitations of traditional therapy.

\section{Limitations}

Various limitations throughout the capstone project may have had an effect on the outcomes presented. First and foremost, time was a limiting factor throughout the entire project. Due to unforeseen circumstances, there were several site cancellations, causing a disruption within the project and its proposed methods and timeline. Securing a site was a lengthy process and had precedence over all other components of the project, including interviews and the survey study. Secondly, although this project provided the doctoral student with valuable information on the perspectives of many health professionals regarding the use of virtual reality, convenience sampling might have had an effect on the findings. A majority of participants were recruited through Facebook. This project also relied on interviews that were not part of survey study. A future recommendation would be to conduct interviews as part of a study with a more targeted population.

Lastly, the doctoral student was unable to secure a site in a pain management setting. This limitation had a direct effect on the outcomes of the project. While the doctoral student was 
able to observe the use of virtual reality at PoNG, the student had to rely on remote interviews and online surveys for information regarding virtual reality's effect on pain management. Future studies would benefit from a capstone experience that included time spent at a pain clinic, where the doctoral student could have conducted more in-person interviews and gathered patient perspectives in addition to therapists. The doctoral student would have also been able to introduce virtual reality to patients and educate staff on its use. Future studies would also benefit from an experience in a pain setting that already applies virtual reality interventions.

\section{Implications for Occupational Therapy}

Findings from this capstone project highlight the impact virtual reality can have as a tool for rehabilitation, and further support the need for awareness and buy-in from occupational therapists working in pain management. Much is already known about occupational therapy’s unique ability to improve and influence the health of individuals and populations suffering from various pain conditions. Decades of evidence have revealed occupational therapy's toolkit for pain management. From guided imagery and gentle exercise, to relaxation techniques in the form of self-hypnosis, meditation, and yoga, occupational therapists working in pain management settings have used variety of traditional treatment methods to help assist their patients in reducing or coping with their pain (Hesselstrand, Samuelsson, \& Liedberg, 2015). However, as demonstrated by the findings from this capstone project, it is of utmost importance that occupational therapists continue to keep up with the latest advances in technology available for rehabilitation. It is time for occupational therapists to seriously consider adding virtual reality to their toolkit.

However, adding virtual reality to one's toolkit is much more than purchasing a headset and a few functional games. Virtual reality is an effective tool for managing pain, but evidence 
from the project's findings also suggest that it's not necessarily about virtual reality but rather how one uses it. Occupational therapists must take the time to learn how virtual reality equipment and programs work so that they can modify them to fit the needs of each individual patient. Collaborating with VR developers and participating in evidence-based research would help. Occupational therapists can especially benefit from taking the time to learn how to design or modify virtual environments. Taking a course on basic virtual reality development would give occupational therapists the ability to design any virtual world imaginable. However, a significant amount of time may be required to acquire those skills. At the very least then, occupational therapists should consider researching a variety of virtual environments (or games) available and becoming experts in selecting specific designs that are most tailored to their patients.

Therefore, while we are beginning to see the potential that virtual reality has for transforming rehabilitation and pain management, more research and education is needed, and occupational therapists must buy into this idea. Virtual reality must be thoughtfully applied in order to have a meaningful role in occupational therapy.

\section{Conclusion}

The goal of this capstone project was to determine and outline the appropriate and potential role of virtual reality within the scope occupational therapy practice concerning pain management. This was done by combining information gathered first through a review of current literature, and subsequently through a capstone experience that included firsthand observations, expert interviews, and the completion of a qualitative survey study. After completing this capstone project, it can be concluded that more buy-in on the part of occupational therapists in order to determine the most appropriate role for virtual reality. As with any emerging 
intervention, there are barriers and other inherent drawbacks that make it difficult for health professionals to implement virtual reality in their own practice settings.

However, even with barriers present, it can be said that virtual reality has "moved through the hype-cycle and is now here to stay" (Ahmadpour et al., 2019). Through this capstone project, it has been determined that a role for virtual reality certainly does exist within the occupational therapy practice. At its most basic, virtual reality can provide occupational therapists with an adjunct tool that incorporates fun and motivation into the rehabilitation process. Virtual reality's greatest attribute, however, may be its unlimited potential as a clientcentered tool for pain management. Occupational therapists already possess advanced skills in designing or modifying environments to fit the needs of their patients (Lagueux, Depelteau, \& Masse, 2018). With virtual reality, the possibilities are endless. Virtual reality may revolutionize the way occupational therapists tailor treatment for their patients. 


\section{References}

Ahmadpour, N., Randall, H., Choksi, H., Gao, A., Vaughan, C., \& Poronnik, P. (2019). Virtual Reality interventions for acute and chronic pain management. The International Journal of Biochemistry \& Cell Biology, 114, 105568. https://doi.org/10.1016/j.biocel.2019.105568

Alazba, A., Al-Khalifa, H., \& AlSobayel, H. (2018). RabbitRun: An immersive virtual reality game for promoting physical activities among people with low back pain. Technologies, (1), 2. https://doi-org.prx-usa.lirn.net/10.3390/technologies7010002

Alemanno, F., Houdayer, E., Emedoli, D., Locatelli, M., Mortini, P., Mandelli, C., et al. (2019)

Efficacy of virtual reality to reduce chronic low back pain: Proof-of-concept of a nonpharmacological approach on pain, quality of life, neuropsychological and functional outcome. PLoS ONE 14(5): e0216858. https://doi.org/10.1371/journal.pone.0216858

Aran, O., Sahin, S., Torpil, B., Demirok, T., \& Kayihan, H. (2017). Virtual reality and occupational therapy. In M. Huri, Occupational Therapy-Occupation Focused Holistic Practice in Rehabilitation. Intech Open. Retrieved from https://www.intechopen.com/books/occupational-therapy-occupation-focused-holisticpractice-in-rehabilitation/virtual-reality-and-occupational-therapy

Baum, C. M., \& Law, M. (1997). Occupational therapy practice: Focusing on occupational performance. American Journal of Occupational Therapy, 51(4), 277-288. https://doi.org/10.5014/ajot.51.4.277

Bolte, B., Lussanet, M. D., \& Lappe, M. (2015). Virtual reality system for the enhancement of mobility in patients with chronic back pain.

Duncan, E. A. S. (2011). The cognitive behavioural frame of reference. In E. A. S. Duncan 
(Ed.), Foundations for practice in occupational therapy (5th ed., pp. 153-164).

Edinburgh: Churchill Livingstone.

Foran, A. C. (2011). Learning from experience: shared constructs in virtual reality and occupational therapy. International Journal of Therapy \& Rehabilitation, 18(7), 362369. Retrieved from http://prxusa.lirn.net/login?url=http://search.ebscohost.com/login.aspx?direct=true $\& \mathrm{db}=\mathrm{ccm} \& \mathrm{AN}$ $=104666920 \&$ site $=$ eds-live

Fowler, C. A., Ballistrea, L. M., Mazzone, K. E., Martin, A. M., Kaplan, H., Kip, K. E., Murphy, J. L., \& Winkler, S. L. (2019). A virtual reality intervention for fear of movement for Veterans with chronic pain: Protocol for a feasibility study. Pilot and Feasibility Studies, 5(1), 146. https://doi.org/10.1186/s40814-019-0501-y

Garcia-Palacios, A., Herrero, R., Vizcaíno, Y., Belmonte, M., Castilla, D., \& Molinari, G. et al. (2015). Integrating virtual reality with activity management for the treatment of fibromyalgia. The Clinical Journal of Pain, 31(6), 564-572. doi:

10.1097/ajp.0000000000000196

Garrett, B., Taverner, T., Masinde, W., Gromala, D., Shaw, C., \& Negraeff, M. (2014). A rapid evidence assessment of immersive virtual reality as an adjunct therapy in acute pain management in clinical practice. The Clinical Journal of Pain, 30(12). Retrieved from https://journals.1ww.com/clinicalpain/Fulltext/2014/12000/A_Rapid_Evidence_Assessme nt_of_Immersive_Virtual.11.aspx

Garrett, B., Taverner, T., \& McDade, P. (2017). Virtual reality as an adjunct home therapy in 
chronic pain management: an exploratory study. JMIR Med Inform, 5(2), e11.

https://doi.org/10.2196/medinform.7271

Gupta, A., Scott, K., \& Dukewich, M. (2018). Innovative technology using virtual reality in the treatment of pain: does it reduce pain via distraction, or is there more to it? Pain Medicine, 19(1), 151-159. Retrieved from http://search.ebscohost.com.prxusa.lirn.net/login.aspx?direct=true $\& d b=s 3 h \& A N=127505011 \&$ site=eds-live

Hesselstrand, M., Samuelsson, K., \& Liedberg, G. (2015). Occupational therapy interventions in chronic pain - a systematic review. Occupational Therapy International, 22(4), 183-194. https://doi.org/10.1002/oti.1396

Hofmann, A. (2018). Living life to its fullest: Managing chronic pain with occupational therapy. Retrieved from https://www.aota.org/About-OccupationalTherapy/Professionals/HW/Articles/Chronic-Pain.aspx

Keefe, F. J., Huling, D. A., Coggins, M. J., Keefe, D. F., Zachary Rosenthal, M., Herr, N. R., \& Hoffman, H. G. (2012). Topical review: Virtual reality for persistent pain: A new direction for behavioral pain management. Pain, 153, 2163-2166. https://doi-org.prxusa.lirn.net/10.1016/j.pain.2012.05.030

Kim, S. S., Min, W. K., Kim, J. H., \& Lee, B. H. (2014). The effects of vr-based wii fit yoga on physical function in middle-aged female lbp patients. Journal of Physical Therapy Science, 26(4), 549-552. doi:10.1589/jpts.26.549

Lagueux, E., Depelteau, A., \& Masse, J. (2018). Occupational therapy’s unique contribution to chronic pain management: a scoping review. Pain Research and Management, 2018, 19. https://doi.org/10.1155/2018/5378451

Li, A., Montaño, Z., Chen, V. J., \& Gold, J. I. (2011). Virtual reality and pain management: 
current trends and future directions. Pain management, 1(2), 147-157.

Mallari, B., Spaeth, E., Goh, H., \& Boyd, B. (2019). Virtual reality as an analgesic for acute and chronic pain in adults: A systematic review and meta-analysis. Journal of Pain Research, Volume 12, 2053-2085. Retrieved from https://doi.org/10.2147/JPR.S200498

Matsangidou, M., Ang, C. S., \& Sakel, M. (2017). Clinical utility of virtual reality in pain management: a comprehensive research review. British Journal of Neuroscience Nursing, 13(3), 133-143. https://doi.org/10.12968/bjnn.2017.13.3.133

McCormack, G. L. (1988). Pain management by occupational therapists. American Journal of Occupational Therapy, 42(9), 582-590. https://doi.org/10.5014/ajot.42.9.582

Nieuwenhuizen, M. G., de Groot, S., Janssen, T. W. J., van der Maas, L. C. C., \& Beckerman, H. (2014). Canadian Occupational Performance Measure performance scale: Validity and responsiveness in chronic pain. Journal of Rehabilitation Research and Development, 51(5), 727-746. Retrieved from https://doi.org/(...)82/JRRD.2012.12.0221

Pain Distraction. (2018). Retrieved October 11, 2019 from https://vrphobia.com/clinical/paindistraction/

Robinson, K., Kennedy, N., \& Harmon, D. (2011). Is occupational therapy adequately meeting the needs of people with chronic pain? American Journal of Occupational Therapy, 65(1), 106-113. https://doi.org/10.5014/ajot.2011.09160

Roosink, M., \& Mercier, C. (2014). Virtual feedback for motor and pain rehabilitation after spinal cord injury. Spinal Cord, 52(12), 860-866. Retrieved from http://prxusa.lirn.net/login?url=http://search.ebscohost.com/login.aspx?direct=true $\& \mathrm{db}=\mathrm{s} 3 \mathrm{~h} \& \mathrm{AN}=$ $99796001 \&$ site=eds-live

Tick, H., Nielsen, A., Pelletier, K. R., Bonakdar, R., Simmons, S., Glick, R., ... Zador, V. 
(2018). Original research: evidence-based nonpharmacologic strategies for comprehensive pain care. The consortium pain task force white paper. EXPLORE, 14, 177-211. https://doi-org.prx-usa.lirn.net/10.1016/j.explore.2018.02.001

Treede, R.-D., Rief, W., Barke, A., Aziz, Q., Bennett, M. I., Benoliel, R., ... Wang, S.-J. (2015). A classification of chronic pain for ICD-11. Pain, 156(6), 1003-1007. https://doi.org/10.1097/j.pain.0000000000000160

Walino-Paniagua, C. N., Gomez-Calero, C., Jimenez-Trujillo, M. I., Aguirre-Tejedor, L., Bermejo-Franco, A., Ortiz-Gutierrez, R. M., \& Cano de la Cuerda, R. (2019). Effects of a game-based virtual reality video capture training program plus occupational therapy on manual dexterity in patients with multiple sclerosis: a randomized controlled trial. Journal of Healthcare Engineering, 2019, 7. https://doi.org/10.1155/2019/9780587

Wittkopf, P. G., Lloyd, D. M., Coe, O., Yacoobali, S., \& Billington, J. (2019). The effect of interactive virtual reality on pain perception: a systematic review of clinical studies. Disability and Rehabilitation, 1-12. https://doi.org/10.1080/09638288.2019.1610803 Wiederhold, B. K., Gao, K., Sulea, C., and Wiederhold, M. D. (2014). Virtual reality as a distraction technique in chronic pain patients. Cyberpsychology, Behavior and Social Networking, 17(6), 346-352.

Wiederhold, B.K., Miller, I. T., \& Wiederhold, M.D. (2018). Using virtual reality to mobilize health care: mobile virtual reality technology for attenuation of anxiety and pain. IEEE Consumer Electronics Magazine, 7(1), 106-109. https://doi.org/10.1109/MCE.2017.2715365 


\section{Appendix A}

Email/Phone Script

Good afternoon

My name is Johnathan Quach and I am a Doctor of Occupational Therapy student at the University of St. Augustine in San Marcos, CA. I am emailing you today because of my interest in your work

I am currently working on my Doctoral Project, which has a focus on exploring Occupational Therapy's Role in Pain Management Using Virtual Reality. Having done preliminary research, I believe that there may be a place for virtual reality as an alternative, non-pharmacologic method of treatment to manage pain during our current pain/opioid crisis.

Thus, as I proceed with the development my project, the next step for me involves finding opportunities survey, interview, and evaluate for interest in virtual reality as well as determining its potential application to occupational therapy's scope of practice for pain management. Unfortunately, literature for this particular idea is scarce, and opportunities to meet and discuss with professionals in the field are even more uncommon.

I realize that you may not have the time or resources to take on a student's request. I am also sure you are very busy, and this email is quite lengthy. However, I would truly appreciate it if you could take some time out of your day to respond to my email. I would also appreciate any advice, guidance, or tips on how/where to proceed with my doctoral project. Hoping to hear back from you at your earliest convenience.

Thank you for your time!

Johnathan Quach

University of St. Augustine for Health Sciences

Doctor of Occupational Therapy Student 


\author{
Appendix B \\ Interview Questionnaire
}

Interview Questions For OT

1. Where are you currently practicing?

2. What is your experience with pain management?

3. Have you worked with patients who have chronic pain?

4. What is your experience with virtual reality?

5. Have you done research on this topic?

a. If they have done research: Can you tell me about some of the studies you were a part of?

6. Have you seen virtual reality in a clinical setting?

7. Are you aware that virtual reality is being used to treat pain?

8. What do you think are some of the perceived benefits of using virtual reality?

9. What populations do you think would benefit from using virtual reality?

10. Do you think there is a role or place for virtual reality in therapy? If so, what role?

11. What do you think are some barriers to VR use?

12. If you have not already, would you be interested in incorporating VR in your own practice?

13. Do you have any recommendations or advice for my project?

Interview Questions for NON-OT (Physical Therapist(s), Psychologist(s) w/ VR Experience)

1. What is your profession?

2. What is your experience with pain management?

3. What is your experience with virtual reality? 
4. Have you done research on this topic?

a. If they have done research: Can you tell me about some of the studies you were a part of?

5. Where have you seen virtual reality used?

6. What do you think are some of the perceived benefits of using virtual reality?

7. What populations do you think would benefit from using virtual reality?

8. Do you think there is a role or place for virtual reality in therapy? If so, what role?

9. What do you think are some barriers to VR use?

10. Do you have any recommendations or advice for my project? 


\section{Appendix C \\ Copy of Online Survey \\ Awareness, Interest and Perception Survey}

As a Doctor of Occupational Therapy Student, I am exploring the use of Virtual Reality for Pain Management within the scope of Occupational Therapy Practice. Having done preliminary research, I believe that there may be a place for virtual reality as an alternative, non- pharmacologic method of treatment to manage pain during our current pain/opioid crisis. As I proceed with the development my project, the next step for me involves finding opportunities to survey and evaluate for interest in virtual reality as well as determining its potential application to occupational therapy's scope of practice for pain management.

You are being asked to participate in a survey that will aid my capstone/doctoral project, which seeks to formulate an appropriate role for the use of virtual reality in OT practice in pain management and to communicate findings to the profession. If you agree to participate in this study, continue by answering the following questions. Please note that by clicking below, you are initiating the survey and indicate your consent to participate. If you do not wish to participate in this study, simply close this window. There are no known risks or benefits to participation in this study. However, the profession may benefit in the future from the information obtained in this research.

This survey will take 10-15 minutes to complete.

If you have any questions related to the content of the survey, you may contact me at $\mathrm{j}$. quach@usa.edu

Johnathan Quach, OTDS

THIS PROJECT HAS BEEN REVIEWED BY THE UNIVERSITY OF ST. AUGUSTINE FOR HEALTH SCIENCES INSTITUTIONAL REVIEW BOARD FOR THE PROTECTION OF HUMAN SUBJECTS.

IF YOU HAVE QUESTIONS OR CONCERNS, PLEASE CONTACT THE INSTITUTIONAL IRB

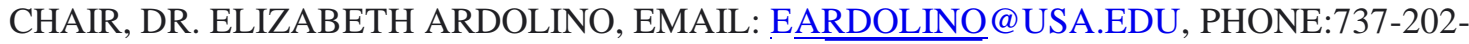
3343.

* Required

\section{General Questions}

Please select the answer that best fits you. 
1. Which of the following applies to you? *

Check all that apply.

Occupation al Therapist Occupational Therapist

Assistant Physical Therapist

Physica Therapist Assistant Other health or

rehab professional OT or PT Student

Other:

2. Are you currently a practicing professional? *

Mark only one oval.

Yes No $\longrightarrow$

Other:

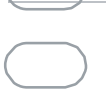

3. If yes, how long have you been practicing?

Mark only one oval.

Less than or equal to 1 year Less than 5 years

6 - 10 years

11 - 20 ears

More than 20 years 
4. Please list your current area(s) of practice, including any areas of expertise and specializations.

\section{Questions related to Virtual Reality}

Virtual Reality (VR) can be described as a simulated, interactive, 3-D environment that allows an individual to experience sensory information, such as vision, touch, and sound, through the use of video-gaming or computer- based systems. These systems typically involve a head-mounted device, a video-capture method, and other special equipment that can provide its users with haptic input (i.e. position, weight, texture of virtual objects). Some VR systems also involve the use of full-room projections that allow an individual to become completely immersed in a virtual environment.

5. Have you ever used or experienced virtual reality for leisure?

Mark only one oval.

Yes No

6. If yes, how would you describe your experience? 
7. Have you ever used or seen virtual reality used in a clinical setting?

Mark only one oval.

Yes No

Unsure

8. If yes, why was virtual reality used? Please describe your thoughts on its use. Please also indicate the type of setting you were in.

9. Are you aware that virtual reality is being used to treat and manage pain?

Mark only one oval.

Yes No

10. If yes, where have you heard about it? If possible, please indicate what setting or population have you heard about it being used with.

11. Do you believe it is important for therapists to keep up-to-date with the latest (evidence-based) advances in technology? Please answer this question by using the 
scale below.

Mark only one oval.

$\begin{array}{lllll}1 & 2 & 3 & 4 & 5\end{array}$

Not at all Important

$\square \bigcirc \square$ Very Important

12. What do you think are some of the perceived benefits of utilizing advanced technology, such as VR, in rehabilitation?

13. In regards to pain management, do you think there is a need for novel treatment strategies to replace or act as an adjunct to traditional medicine/rehabilitation?

Mark only one oval.

Yes No

Unsure 
14. How interested are you in learning more about virtual reality and how it can help manage pain?

Mark only one oval.

1

$\begin{array}{llll}2 & 3 & 4 & 5\end{array}$

Not at all interested

$\square \square \square \square$ Very interested

15. How interested are you in incorporating the use of virtual reality in your own setting?

Mark only one oval.

$1 \quad \begin{array}{lllll}2 & 3 & 4 & 5\end{array}$

Not at all interested

Very interested

16. Lastly, what do you feel are some barriers that may affect the use of virtual reality in clinical settings? 
This content is neither created nor endorsed by Google.

Forms le 


\author{
Appendix D \\ Weekly Facebook Post/Advertisement for Online Survey
}

Hello all,

My name is Johnathan Quach and I am conducting an online survey in order to gather data on the awareness, interest, and perspectives from our community of therapists on the use of virtual reality for pain management. Your input will provide me with valuable information regarding on the potential application of virtual reality within the scope of occupational therapy practice, especially in regard to pain management.

The survey consists of 16 question and should take 10-15 minutes to complete. Please click on the link below for more information, and to access the survey.

https://forms.gle/WAG3s1F82LyWwfx58

Thank you so much for your time! 
Appendix E

Screenshots of Created VR Scenes 


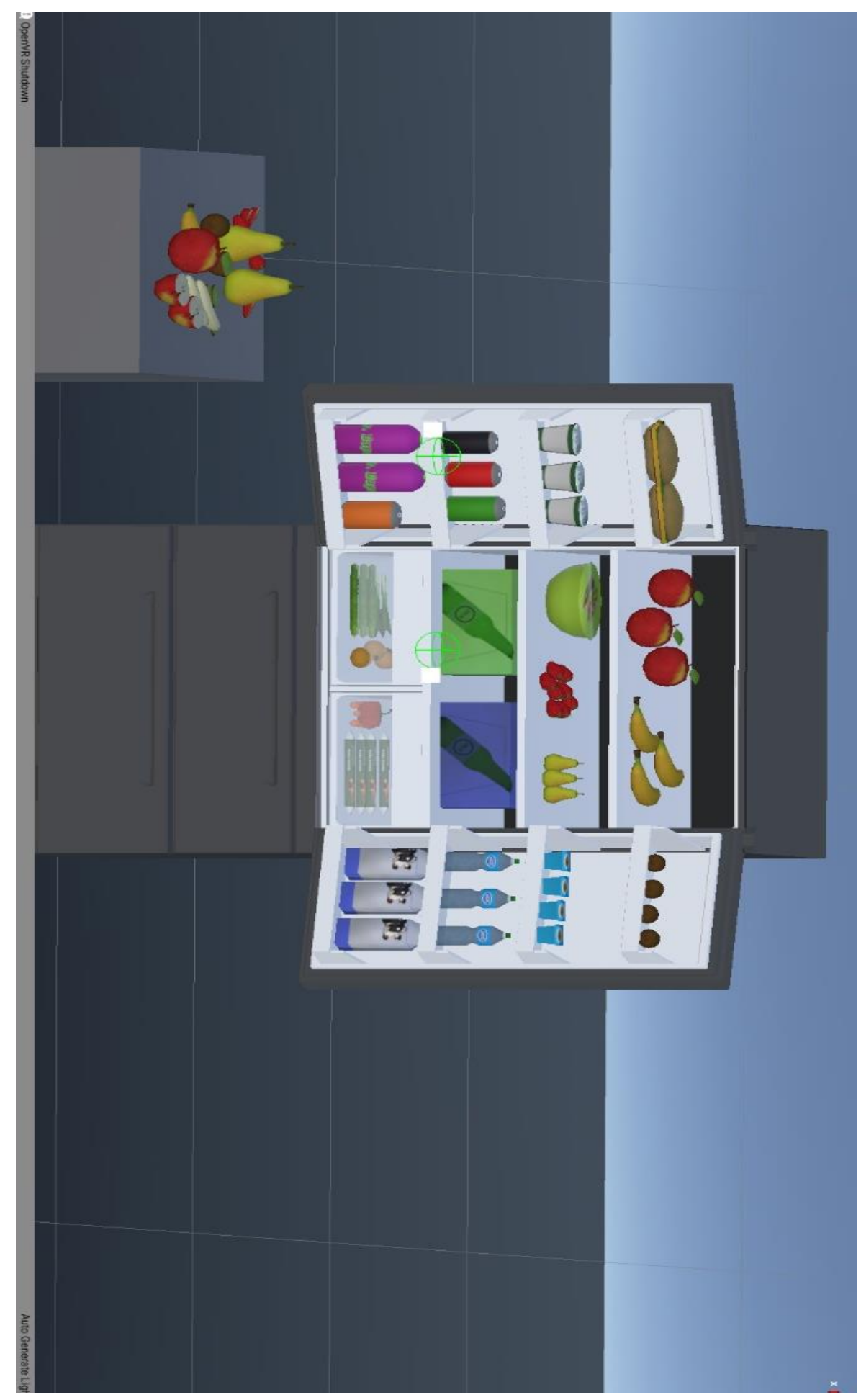




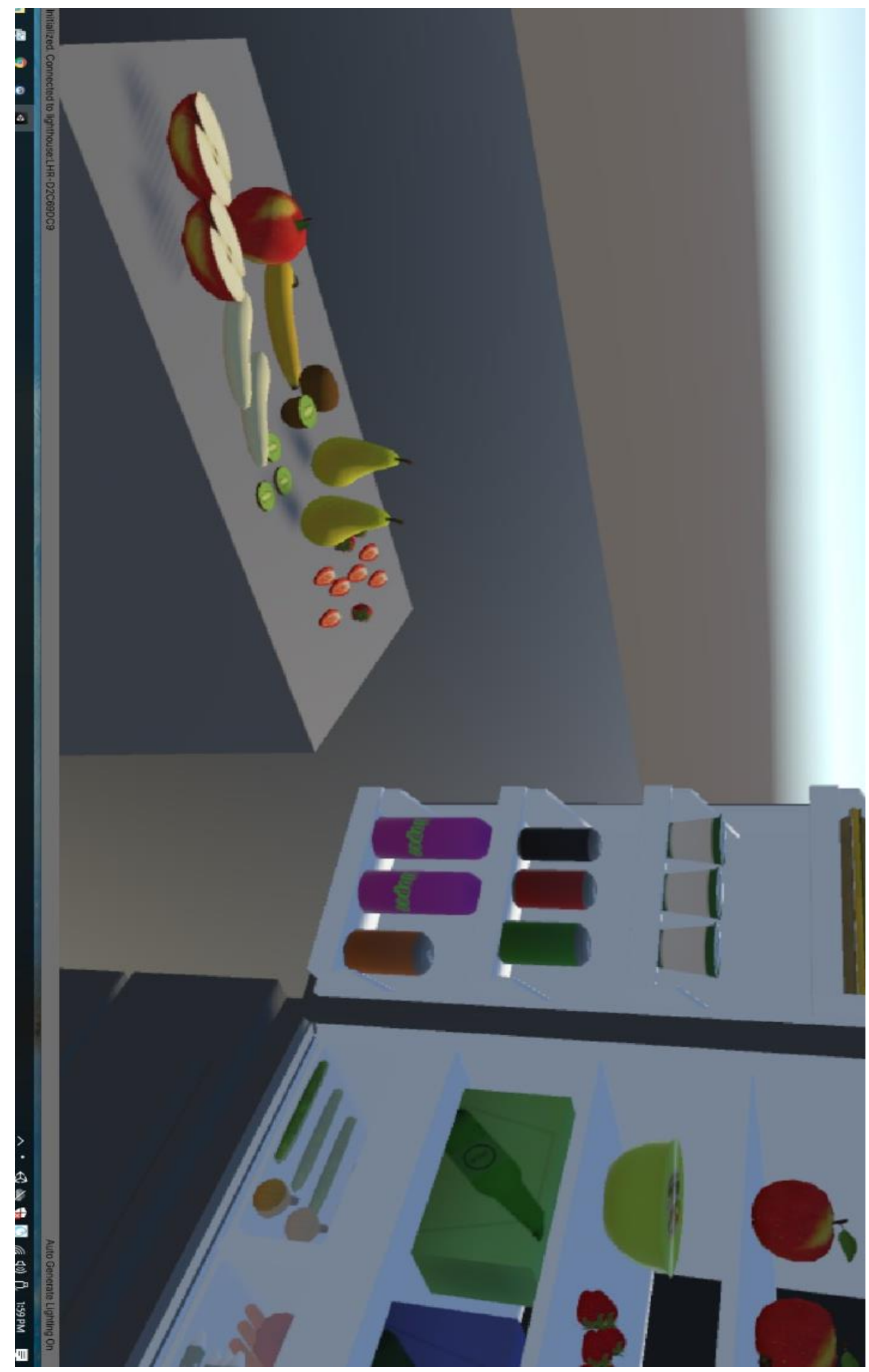




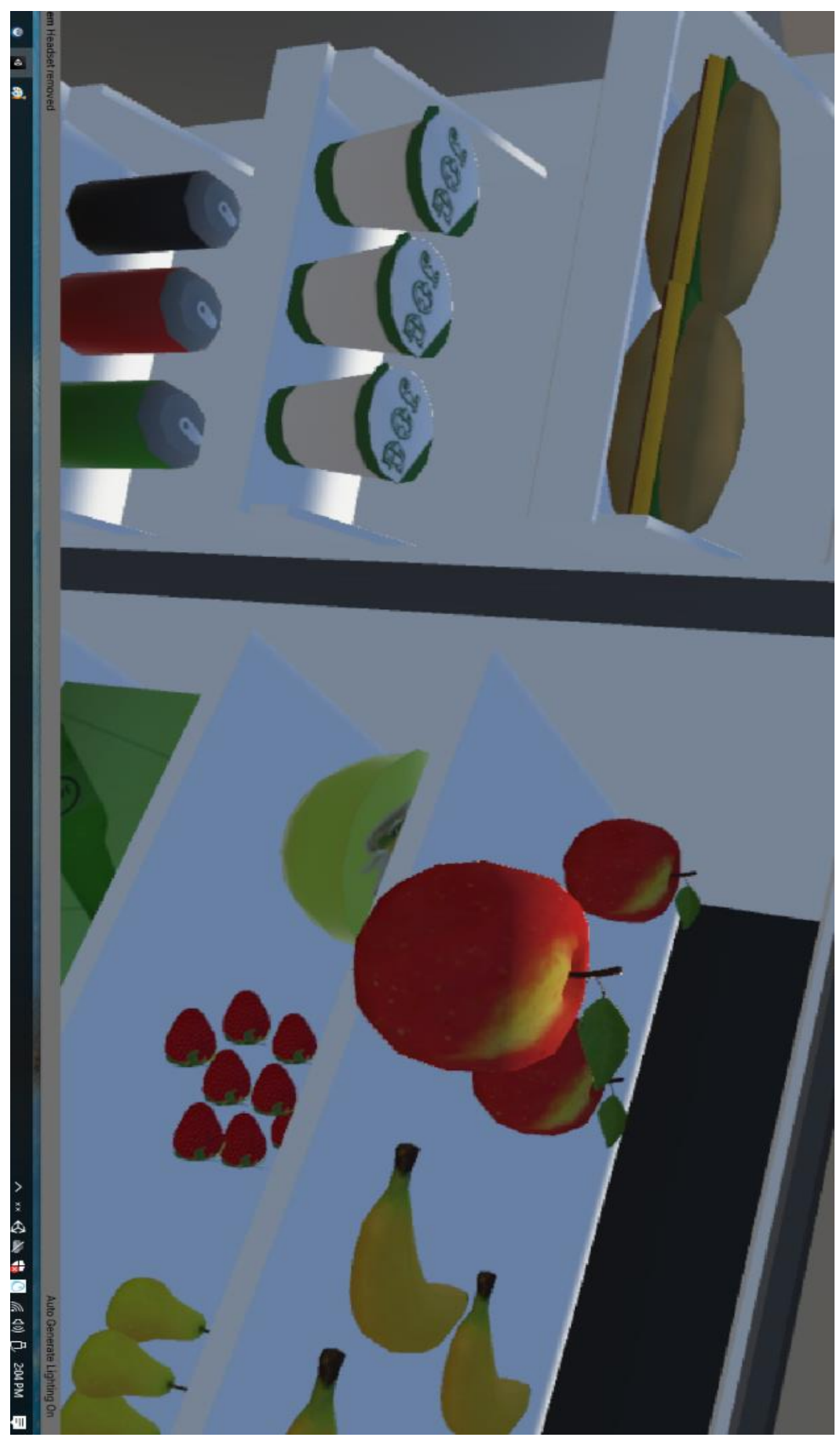




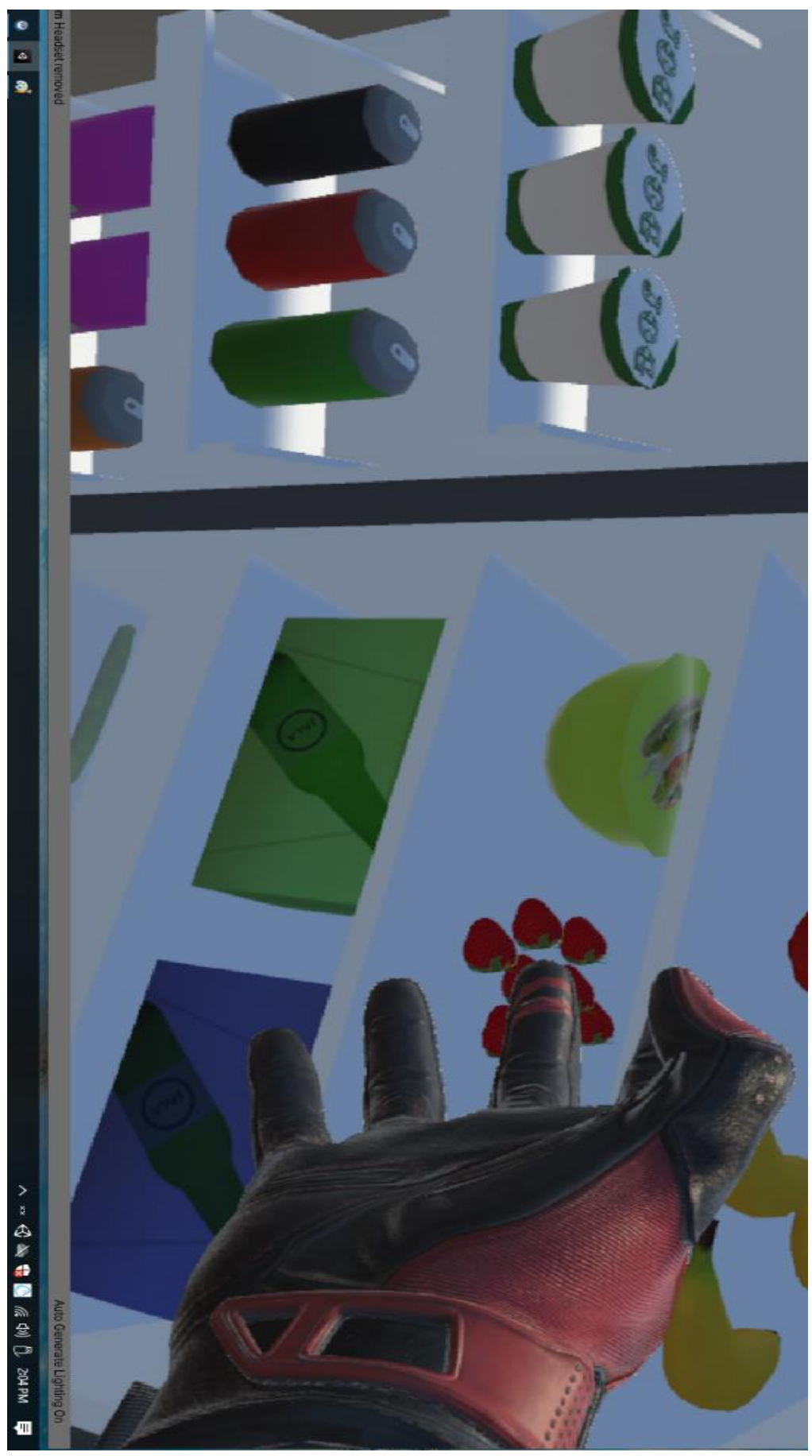


Appendix F

Informational Handout on VR 


\section{What is VIRTUAL REALITY?}

By Johnathan Quach, Doctor of Occupational Therapy Student

Virtual Reality (VR) is a technology that immerses or transports individuals into a simulated, interactive, 3-D environment and allows them to experience sensory information, such as vision, touch, and sound, through the use of videogaming or computerbased systems. Virtual reality systems typically involve a head-mounted device, a video-capture method, and special equipment that provide its users haptic input (i.e. position, weight, texture of virtual objects).

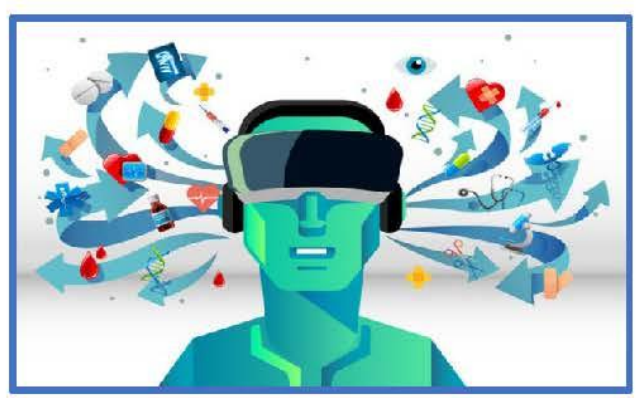

(Matsangidou, Ang \& Sakel, 2017; Roosink \& Mercier, 2014; Foran, 2011)

\section{HOW DOES VIRTUAL REALITY HELP WITH PAIN MANAGEMENT?}

1. Pain Distraction via "Gate Control" Theory

2. Addressing Fear Avoidance (Kinesiophobia)

(Alazba, Al-Khalifa \& AlSobayel, 2018; Li et al., 2011)

VR has the ability to reduce pain by exerting an array of emotional, cognitive and attentional processes on the body's intricate pain modulation system. Put into an immersive, virtual world, patients are able to perform prescribed physical activities while distracted from pain.

To date, numerous studies have been conducted involving the use of VR as an effective adjunct and alternative to conventional analgesic. These studies include:
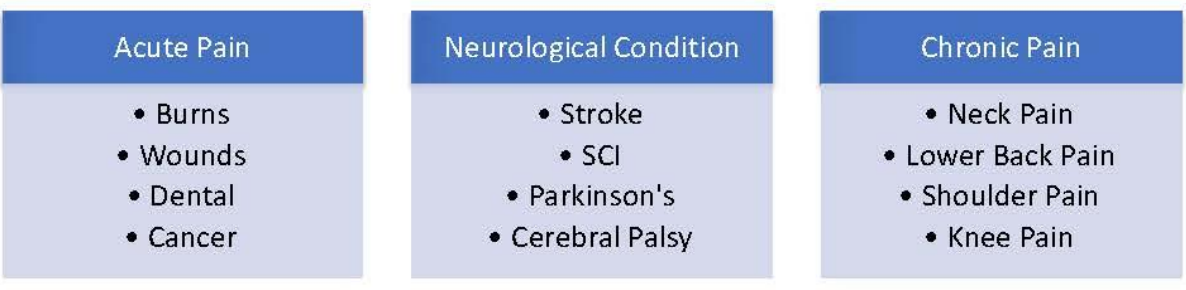

\section{WHY USE VIRTUAL REALITY IN OCCUPATIONAL THERAPY?}

1. VR can provide context that is ecologically valid and safe

2. VR allows us to take therapy anywhere

3. VR enables clinicians to better understand the patient experience

4. VR can help establish better connections in the brain

5. VR environments can be tailored to meet all kinds of needs - particularly pain. 
Many individuals suffer from chronic pain and much of that pain is under-treated or treated ineffectively. There has been a call to action to:

- Increase awareness of effective nonpharmacologic treatments for pain

- Train healthcare practitioners and administrators in evidence-based no npharmacologic practice

- To promote ongoing research and dissemination on the role of effective nonpharmacologic treatments in pain

(Tick, et al.,20 18)

\section{Occupational Therapy should be a part of this call to action!}

Pain is infinitely complex, and occupational therapists are experts at assessing and understanding its many dimensi ons in relation to their patients.

Pain, especially chronic pain, can lead to:

- Anxiety, depression

- Decreased self-efficacy

- Increased dependency

- Loss of work and family roles

- Difficulty participating in daily, meaningful occupations

- An overall reduced quality of life

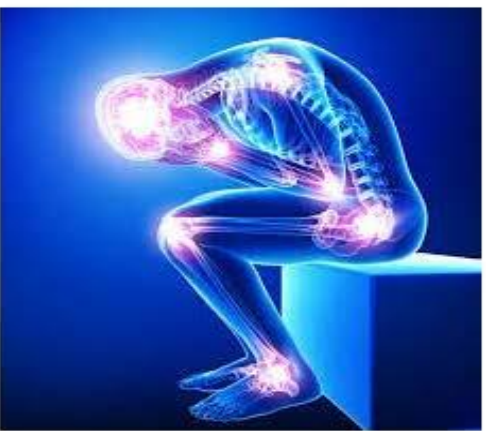

With a patient-centered focus on enhancing function and enabling occupation, occupational therapi sts working as part of a pain management team can tail or virtual environments and utilize VR's ability to help change the way patients cope with pain on a daily basis and more importantly, restore their ability to engage in meaningful occupations (Foran, 2011).

\section{WHAT VIRUAL REALITY TECHNOLOGIES ARE CURRENTLY AVAILABLE?}

There are currently three different types of VR headsets available: Mobile, tethered, or standalone headsets.

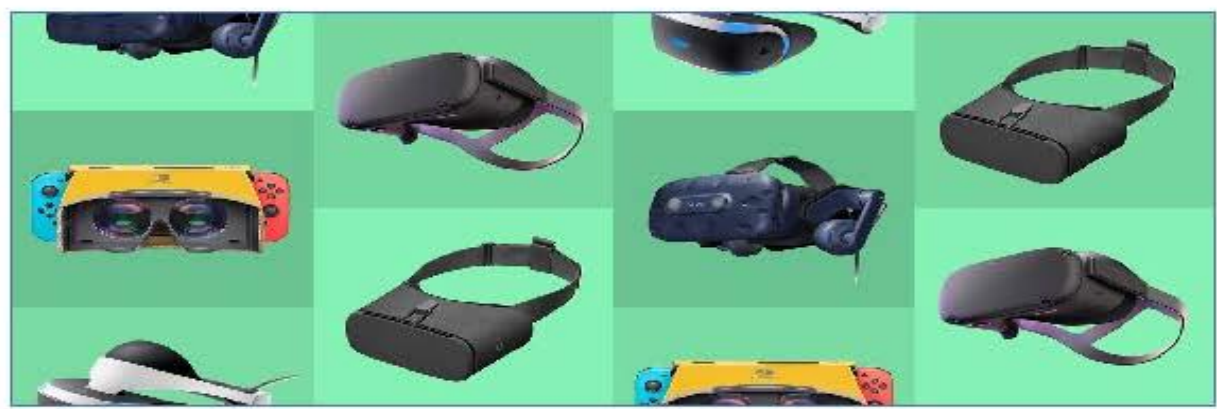



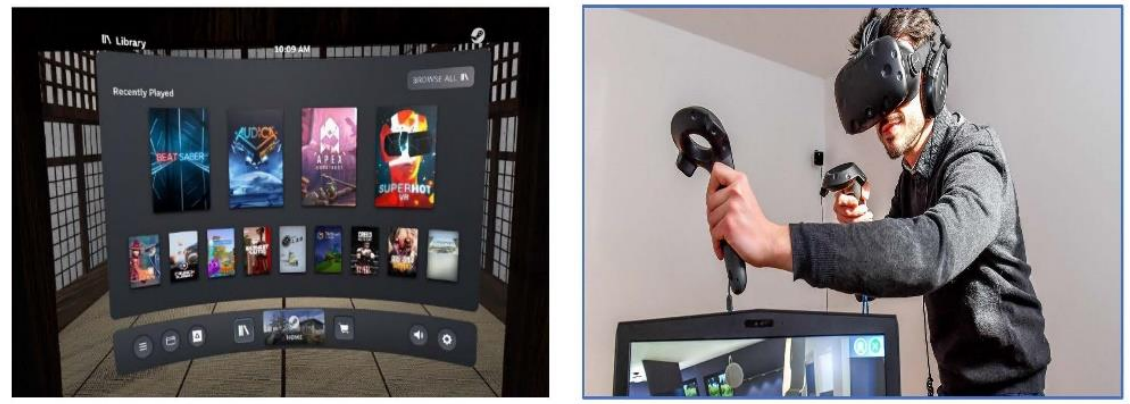

Mobile headsets are shells with lenses that attaches to a smartphone device. The lenses separate the screen into two images (one per eye), turning a smartphone device into a VR device. Various games have been developed for free or for purchase on each of the following platforms.

1. Samsung Gear VR $\sim \$ 100$

2. Google Daydream View $\sim \$ 75$

3. Nintendo Labo VR Kit $\sim \$ 80$

*these prices do not include required smartphone device

Tethered headsets are headsets that act as a display device to another device, like a PC or a video game console, to provide a virtual reality experience. Tethered headsets are much more immersive than mobile headsets because they offer six-degrees-of-freedom (6DOF) motion tracking and dual motion controllers (compared to three-degrees-of-freedom (3DOF) motion tracking and only one motion controller). Tethered headsets must be physically connected to a device via cables and can be bulky.

Tethered headsets are the most expensive kind of headsets but offer a wide range of options and features that may be useful when selecting games or environments that fit a patient's needs.

1. HTC Vive Pro $\sim \$ 800$

2. Valve Index $\sim \$ 1,000$

3. Oculus Rift $\mathrm{S} \sim \$ 400$

4. PlayStation $\mathrm{VR} \sim \$ 300$

*these headsets do not include PC or console required

Standalone headsets are just as the name implies. These headsets do not require a smartphone device and do not need to be physically connected to any computer or game console. Standalone headsets are the latest in modern VR technology. Several options now offer the same compelling, immersive VR experience as tethered headsets, without the unwieldy cables.

Standalone headsets have less processing power than their tethered counterparts, and are currently limited by their software store, which has fewer game selections built in.

1. Oculus Quest $\sim \$ 400-500$

2. HTC Vive Focus Plus $\sim \$ 799$

3. Lenovo Mirage Solo $\sim 200$

*none of the headsets listed above include prices for optional, downloadable games 
HOW SHOULD VIRTUAL REALITY BE USED IN OCCUPATIONAL THERAPY?

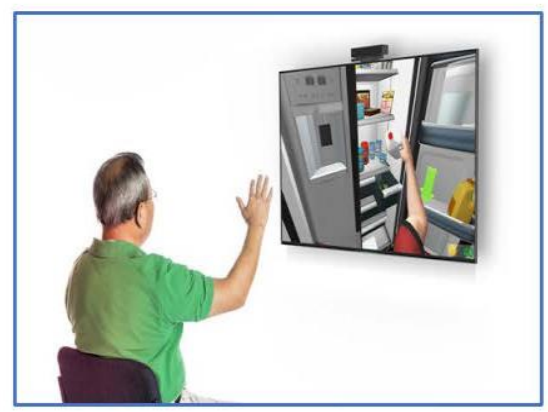

An occupation -based VR game for meal prepping and performing cooking tasks.

Occupational therapists should ask:

- What are the goals of therapy?

- What type of environments would support the patient or client's occupational performance?

- What activities are most important?

- What are the activity demands?

- Context and client factors must also be considered.

- How can treatment be as client-centered as possible?

Occupational therapists should determine:

- What virtual reality equipment or games are available?

- How can I thoughtfully apply VR to support my client's functional needs?

- What aspects of this virtual "game" should be used?

- Are there ways to grade the activities within the game?

\section{PUTTING IT TOGETHER}

The use of virtual reality for pain management within the scope of occupational therapy practice is still in its inception. More evidence-based research is needed to support its use in pain management. However, through the lens of an occupational therapist, virtual reality can be a purposeful treatment method that reduces the need for painkillers while maximizing the capacity for engagement in meaningful activities.

Once known for its use as an entertainment tool, VR has the potential to become a valuable therapeutic tool in the field of healthcare and pain management. 


\section{References}

Aran, O., Sahin, S., Torpil, B., Demirok, T., \& Kayihan, H. (2017). Virtual Reality and Occupational Therapy. In M. Huri, Occupational Therapy - Occupation Focused Holistic Practice in Rehabilitation. Intech Open. Retrieved from https://www.intechopen.com/books/occupational-therapy-occupation-focused-holisticpractice-in-rehabilitation/virtual-reality-and-occupational-therapy

Alazba, A., Al-Khalifa, H., \& AlSobayel, H. (2018). RabbitRun: An immersive virtual reality game for promoting physical activities among people with low back pain. Technologies, (1), 2. https://doi-org.prx-usa.lirn.net/10.3390/technologies7010002

American Occupational Therapy Assocation. (2014). Occupational therapy and pain management [PDF]. Retrieved from https:/www.aota.org/ /media/Corporate/Files/AboutOT/Professionals/WhatIsOT/HW/Fa cts/Pain\%20Rehabilitation\%20fact\%20sheet.pdf

Foran, A. C. (2011). Learning from experience: shared constructs in virtual reality and occupational therapy. International Journal of Therapy \& Rehabilitation, 18(7), 362 369. Retrieved from

http://prxusa.lirn.net/login?url=http://search.ebscohost.com/login.aspx?direct $=$ true $\& \mathrm{db}=\mathrm{c}$ cm\&AN

$=104666920 \&$ site $=$ eds-live

Li, A., Montaño, Z., Chen, V. J., \& Gold, J. I. (2011). Virtual reality and pain management: current trends and future directions. Pain management, l(2), 147-157.

Matsangidou, M., Ang, C. S., \& Sakel, M. (2017). Clinical utility of virtual reality in pain management: a comprehensive research review. British Journal of Neuroscience Nursing, 13(3), 133-143. https://doi.org/10.12968/bjnn.2017.13.3.133

Tick, H., Nielsen, A., Pelletier, K. R., Bonakdar, R., Simmons, S., Glick, R., ... Zador, V. (2018). Original research: evidence-based nonpharmacologic strategies for comprehensive pain care. The consortium pain task force white paper. EXPLORE, 14, 177-211. https://doi-org.prx-usa.lirn.net/10.1016/j.explore.2018.02.001 